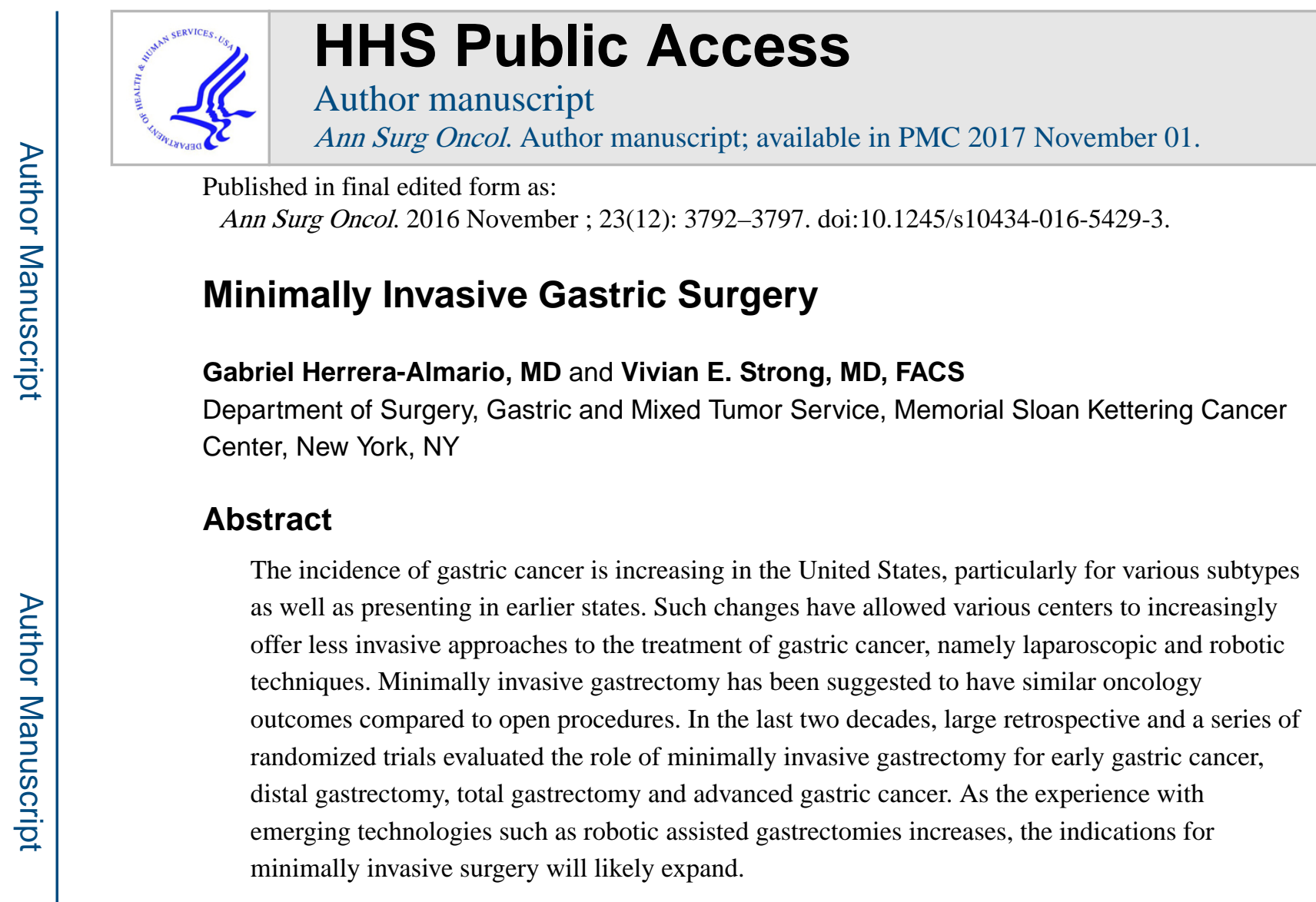

Gastric carcinoma has been declared a global health concern by the World Health Organization (WHO) and is now the second leading cause of cancer deaths worldwide, with nearly 1,000,000 cases annually. ${ }^{1}$ Although the rates are highest in Japan, China, Eastern Europe and South America, the incidence in the US is also increasing, particularly for various subtypes of gastric carcinoma. In particular, gastroesophageal junction (GEJ) cancers are steadily increasing among various ethnic groups in the $\mathrm{US},{ }^{1}$ as are non-cardia gastric cancers in young Americans (25-39 years of age), where there has been a $70 \%$ increase in incidence. ${ }^{2}$ At various high-volume gastric cancer institutions such as ours, we have also noted a shift in the presentation of gastric cancer. Whereas during the time period 1985-1995 only $20 \%$ of patients presenting to our institution had early-stage disease (stage 1), in a more recent time period (2006-2010) that number has doubled to approximately $40 \%$. Such changes have allowed us, as a center, to explore and increasingly offer less invasive approaches to the treatment of gastric cancer, namely laparoscopic and robotic techniques.

Minimally invasive gastrectomy has been suggested to have similar oncologic outcomes compared with open procedures, ${ }^{3}$ thus becoming an ideal alternative to enable patients a faster return to routine activities. In addition, earlier recovery allows patients to receive adjuvant systemic chemotherapy earlier. ${ }^{4}$ It is important for surgeons caring for gastric cancer patients to evaluate the evidence comparing the laparoscopic and open procedure for distal and total gastrectomy, its role in early and advanced gastric cancer, key differences between Eastern and Western series, learning curves associated with this advanced laparoscopic procedure, and its role in emerging technologies such as robotic-assisted procedure. 


\section{LAPAROSCOPIC GASTRECTOMY FOR EARLY GASTRIC CANCER}

Since laparoscopic gastrectomies were first described in the mid 1990s, there has been a continuous expansion in the use, indications, and technical innovations of this technique. Laparoscopic-assisted distal gastrectomy (LADG) for early gastric cancer was introduced by Kitano et al. in $1994^{5}$ using an abdominal lift technique. Subsequently, retrospective series in the early 2000s emerged from Eastern countries and showed encouraging results with this approach for early gastric cancer, especially in regard to pain medication use, length of hospital stay, and blood loss, but mixed results in regard to lymph node retrieval. ${ }^{6-10}$ These studies set the stage for a series of randomized controlled trials reported in the first decade of the 2000s.

The first randomized trial for laparoscopic distal gastrectomy was published by Kitano et al. ${ }^{11}$ in 2002. Twenty-eight patients with early gastric cancer were randomized to either open distal gastrectomy (ODG) or LADG. Patients in both groups were similar in regard to demographic variables, tumor location, and staging, but blood loss was less in the LADG group. Patients in the laparoscopic intervention group also had an earlier recovery of bowel function, and pain score also showed improvement in the laparoscopic group.

In 2005, three subsequent trials were published. Lee et al. ${ }^{12}$ evaluated 47 patients who had early gastric cancer and were randomized to ODG or LADG. Blood loss and transfusion requirements were similar in both groups, and no significant difference was found in length of stay. The mean number of lymph nodes retrieved was 38.1 for the open group versus 31.8 in the laparoscopic group. Postoperative complications were more frequent in the open group. At a median follow-up of 14 months, no recurrence was noted in any group. Hayashi et al. ${ }^{13}$ reported on a trial in 28 patients -14 randomized to LADG and 14 to ODG for early gastric cancer. LADG required shorter postoperative epidural anesthesia, no major complications, and surgery was equally radical in the two groups. Huscher et al. ${ }^{14}$ reported on 59 patients randomized to LADG $(n=30)$ or ODG $(n=29)$. No significant differences were found when evaluating demographic characteristics, American Society of Anesthesiologists (ASA) score, TNM stage, duration of surgery, and number of resected lymph nodes. Higher blood loss was observed in the ODG arm, and an earlier discharge was noted in the LADG arm. Five-year overall survival and disease-free survival rates were 55.7 and $54.8 \%$ and 58.9 and $57.3 \%$, respectively, which were not statistically different. ${ }^{14}$

Subsequently, in 2008, Kim et al. ${ }^{15}$ reported outcomes on 164 patients randomized to LADG $(n=82)$ versus ODG $(n=82)$. A decrease in estimated blood loss (EBL), total amount of analgesia, and length of postoperative hospital stay was noted. In addition, a significant difference in the number of lymph nodes retrieved (29 vs. 45.1) was observed but this number was above recommended lymph node harvesting. A relevant feature of this trial was the improvement in quality of life outcomes favoring LADG. In 2013, Sakuramoto et al. ${ }^{16}$ reported outcomes of patients with early gastric cancer randomized to ODG or LADG performed by high-volume surgeons. A significant decrease in the use of analgesics ( $p=$ 0.022), as well as a decrease in postoperative complications, was seen in the LADG group. No differences were noted in lymph node retrieval between the two groups. 
The above-mentioned studies have been criticized because they are single-institution reports with a limited number of patients and are mostly composed of Eastern populations (except the study by Huscher et al. ${ }^{14}$ from Italy). In an effort to address these concerns, the Korean Laparoscopic Gastrointestinal Group (KLASS) designed a phase III, multicenter, prospective, randomized trial (KLASS trial) to evaluate short- and long-term outcomes for patients with early gastric cancer treated either by LADG or ODG. An interim analysis of morbidity and mortality outcomes ${ }^{17}$ was reported in 2010, and a total of 342 patients had been randomized 179 to LADG and 163 to ODG. Less blood loss was seen in the LADG group. The postoperative complication rate was $10.5 \%$ for the LADG group versus $14.7 \%$ for the ODG group $(p=0.137)$. Mortality was $1.1 \%$ for the LADG group and 0 for the ODG group ( $p=0.497$ ). Short-term outcomes from this trial were updated and published in a 2016 trial, 18 which included a total of 1416 patients enrolled between 2006 and 2010705 in the LADG group and 711 in the ODG group. No major differences in demographic variables, comorbidities, tumor location, tumor size, and pathological stage were noted between the two groups. With regard to intraoperative variables, no significant differences were observed in the extent of resection, multiorgan resection, and intraoperative transfusion rates. LADG was associated with decreased EBL when compared with ODG (190 mL vs. $156 \mathrm{~mL} ; p<0.001)$. The average number of lymph nodes was slightly higher in the ODG group ( 40.5 vs. $43.7 ; p=0.001$ ), and the length of hospital stay was shorter in the LADG group (7.1 vs. 7.9 days; $p<0.001$ ). The overall complication rate was lower for the LADG group versus the open group ( 13 vs. $19.9 \% ; p=0.001$ ), and the mortality rate was similar between the two groups $(0.6$ vs. $0.3 \%) .{ }^{18}$ Selected studies are summarized in Table 1.

\section{LAPAROSCOPIC GASTRECTOMY FOR ADVANCED GASTRIC CANCER}

Laparoscopic gastrectomy has also been used for total gastrectomies and advanced gastric cancer. In 1999, Azagra et al. reported the first total laparoscopic total gastrectomy for cancer, ${ }^{19}$ while total laparoscopic-assisted gastrectomy with D2 lymphadenectomy was also described in 1999. ${ }^{20}$ Large retrospective series have also evaluated the use of laparoscopic gastrectomy for advanced gastric cancer. In 2013, Shinohara et al. ${ }^{21}$ reported their experience in 336 patients who had undergone a laparoscopic or open gastrectomy for clinical stage T2-T4. The laparoscopic cohort included 186 patients, and 123 patients from the open cohort were matched. Laparoscopic D2 gastrectomy was associated with less blood loss and shorter hospital stay. The mortality rate was similar (1.1 vs. $0 \% ; p=0.519)$ between groups, and the complication rate was $24.2 \%$ for the laparoscopic group vs. $28.5 \%$ for the open group $(p=0.402)$. Five-year disease-free survival was $65.8 \%$ for the laparoscopic group versus $62 \%$ in the open group $(p=0.737) .{ }^{21}$ The authors concluded that laparoscopic gastrectomy for advanced gastric cancer was an alternative to the open procedure. In a multicenter, retrospective study, Park et al. ${ }^{22}$ reported similar outcomes for LADG for advanced gastric cancer, which was comparable with prior open gastrectomy series. Lee et al. ${ }^{23}$ reported outcomes on 94 patients who underwent laparoscopic total gastrectomy for advanced gastric cancer. The median lymph node harvest was 61 nodes. Major morbidity was recorded in $9.6 \%$ of patients, and no mortalities were recorded. In 2011, Cai et al. ${ }^{24}$ reported the results of their prospective, randomized study comparing open and laparoscopic radical gastrectomy for advanced gastric cancer. Patients in both groups 
were similar with regard to demographic data. The morbidity rate was $12.2 \%$ in the LAG group versus $19.1 \%$ in the open group, and no overall survival difference was found between the groups $(67.1$ and $53.8 \% ; p=0.911)$.

Fewer reports from Western countries are available. In 2009, Strong et. al. ${ }^{25}$ published the initial laparoscopic experience in a high-volume center. Thirty patients identified from a prospectively kept database were matched to 30 patients treated with open subtotal gastrectomy. Patients in both groups did not differ in regard to demographics and stage. Importantly, only $55 \%$ of patients were stage Ia/Ib. Laparoscopic surgery was associated with a decrease in length of stay and a trend towards a decrease in early (26 vs. $43 \% ; p=$ 0.07 ) and late complications ( 0 vs. $20 \% ; p=0.03$ ). An important finding of this study was that oncologic outcomes were comparable with those of the open approach in regard to margin status and lymph node retrieval.

Vinuela et al. ${ }^{3}$ performed a meta-analysis of randomized controlled trials and high-quality, non-randomized studies evaluating laparoscopic versus open distal gastrectomy. Laparoscopic distal gastrectomy was associated with overall lower complications (odds ratio [OR] 0.59; $p<0.001$ ), medical complications (OR 0.49; $p=0.002$ ), and decreased length of stay. Although patients in the LADG group had a lower number of lymph nodes retrieved (weighted mean difference $3.9 ; p<0.001$ ), the proportion of patients with less than 15 nodes was similar (OR 1.26; $p=0.09){ }^{3}$ A key finding of this meta-analysis was that the overall incidence of complications was lower in the LADG group compared with the ODG group. Kelly et al. ${ }^{4}$ reported, from our group outcomes, on 87 patients undergoing laparoscopicassisted gastrectomies and 87 patients undergoing open gastrectomy. The laparoscopic approach was associated with less blood loss, decreased duration of narcotic and epidural use, and, importantly, a decreased incidence of minor (27 vs. $16 \%$ ) and late (17 vs. $7 \%$ ) complications when compared with the open approach. This is associated with a higher likelihood of receiving adjuvant therapy, which is relevant in patients in the West, who usually present with more advanced disease. Selected studies are summarized in Table 1.

\section{KEY DIFFERENCES BETWEEN EASTERN AND WESTERN SERIES}

When evaluating the available published data in type of approach and laparoscopic surgery for gastric cancer, it is important to consider several differences in the presentation of the disease between Eastern and Western series. In a comparison of outcomes and survival from two high-volume centers in the US and Korea, ${ }^{26}$ several differences were appreciated between patients. With regard to tumor location, upper or GEJ location was present in $39 \%$ of patients in the US compared with only $9.4 \%$ of Korean patients. Additional differences were identified in type of tumor according to Lauren classification, $\mathrm{T}$ stage, $\mathrm{N}$ stage, and lymph node retrieval. In multivariate analysis, patients in Korea had better survival (hazard ratio $1.3,95 \%$ confidence interval $1-1.6 ; p=0.008$ ) and multiple reasons have been proposed to explain these differences. ${ }^{26}$ 


\section{ROBOTIC SURGERY FOR GASTRIC CANCER}

Robotic platforms have been used since the early 2000s for the treatment of gastric cancer. As early as 2002, Hashizume et al. ${ }^{27}$ suggested that robotic systems could aid in performing more precise minimally invasive surgery. The number of publications on the use of robotic surgery for gastric cancer has increased. It has also been suggested that robot-assisted gastrectomy may be easier to learn than laparoscopic-only gastrectomy. ${ }^{28} \mathrm{~A}$ recent metaanalysis compiled available evidence from prior studies, comprising 1875 patients operated with robotic gastrectomy, showing lower EBL, longer distal margin, and similar harvested lymph nodes. ${ }^{29}$

\section{LEARNING CURVE IN LAPAROSCOPIC GASTRECTOMY}

Laparoscopic gastrectomy is a technically demanding procedure that requires advanced skills and teamwork. Multiple authors have shown that the learning curve for laparoscopic gastrectomy can vary from 40 to 100 cases. ${ }^{30-33}$ Given the potential benefits of threedimensional imaging, articulating instruments, and functional imaging, further trials will need to explore the benefits of robot-assisted gastrectomy, which may potentially shorten the learning curve associated with the laparoscopic-only approach. This training is key because currently limited application is related to the relatively low numbers of gastric cancer cases in most institutions. This approach may therefore facilitate more widespread use of minimally invasive surgery for stomach cancer.

\section{CONCLUSION}

We aimed to demonstrate that minimally invasive approaches for appropriately selected gastric cancer patients have a substantial and undeniably beneficial place in the armamentarium of treatment for gastric cancer patients. Clearly, some gastric cancers require an open approach, especially for larger, more advanced tumors, for patients with clear invasion into surrounding organs or for those in which the surgeon requires tactile feedback that is currently not available for robotic platforms. However, for patients with early gastric cancers, for those harboring the $\mathrm{CDH} 1$ mutation requiring total gastrectomy, and even for some with locally advanced tumors who have completed neoadjuvant treatment, the application of this technology has a role and should be considered. However, technological advances should never take precedence over the surgeon's judgment of the best oncologic procedure that can be offered to a patient. As more and more surgical oncologists continue to explore minimally invasive approaches and gain comfort with this tool, the indications for application will likely expand.

\section{Acknowledgments}

FUNDING This study was supported in part by National Institutes of Health/National Cancer Center (NIH/NCI) Cancer Center Support Grant P30 CA008748.

\section{REFERENCES}

1. Jemal A, Bray F, Center MM, Ferlay J, Ward E, Forman D. Global cancer statistics. CA Cancer J Clin. 2011; 61(2):69-90. [PubMed: 21296855]

Ann Surg Oncol. Author manuscript; available in PMC 2017 November 01. 
2. Anderson WF, Camargo MC, Fraumeni JF Jr, Correa P, Rosenberg PS, Rabkin CS. Age-specific trends in incidence of noncardia gastric cancer in US adults. JAMA. 2010; 303(17):1723-1728. [PubMed: 20442388]

3. Vinuela EF, Gonen M, Brennan MF, Coit DG, Strong VE. Laparoscopic versus open distal gastrectomy for gastric cancer: a meta-analysis of randomized controlled trials and high-quality nonrandomized studies. Ann Surg. 2012; 255(3):446-456. [PubMed: 22330034]

4. Kelly KJ, Selby L, Chou JF, Dukleska K, Capanu M, Coit DG, et al. Laparoscopic versus open gastrectomy for gastric adenocarcinoma in the West: a case-control study. Ann Surg Oncol. 2015; 22(11):3590-3596. [PubMed: 25631063]

5. Kitano S, Iso Y, Moriyama M, Sugimachi K. Laparoscopy-assisted Billroth I gastrectomy. Surg Laparosc Endosc. 1994; 4(2):146-148. [PubMed: 8180768]

6. Adachi Y, Shiraishi N, Shiromizu A, Bandoh T, Aramaki M, Kitano S. Laparoscopy-assisted Billroth I gastrectomy compared with conventional open gastrectomy. Arch Surg. 2000; 135(7): 806-810. [PubMed: 10896374]

7. Shimizu S, Uchiyama A, Mizumoto K, Morisaki T, Nakamura K, Shimura H, et al. Laparoscopically assisted distal gastrectomy for early gastric cancer: is it superior to open surgery? Surg Endosc. 2000; 14(1):27-31. [PubMed: 10653231]

8. Tanimura S, Higashino M, Fukunaga Y, Osugi H. Hand-assisted laparoscopic distal gastrectomy with regional lymph node dissection for gastric cancer. Surg Laparosc Endosc Percutan Tech. 2001; 11(3):155-160. [PubMed: 11444743]

9. Yano H, Monden T, Kinuta M, Nakano Y, Tono T, Matsui S, et al. The usefulness of laparoscopyassisted distal gastrectomy in comparison with that of open distal gastrectomy for early gastric cancer. Gastric Cancer. 2001; 4(2):93-97. [PubMed: 11706767]

10. Choi SH, Yoon DS, Chi HS, Min JS. Laparoscopy-assisted radical subtotal gastrectomy for early gastric carcinoma. Yonsei Med J. 1996; 37(3):174-180. [PubMed: 8826782]

11. Kitano S, Shiraishi N, Fujii K, Yasuda K, Inomata M, Adachi Y. A randomized controlled trial comparing open vs laparoscopy-assisted distal gastrectomy for the treatment of early gastric cancer: an interim report. Surgery. 2002; 131(1 Suppl):S306-S311. [PubMed: 11821829]

12. Lee JH, Han HS, Lee JH. A prospective randomized study comparing open vs laparoscopy-assisted distal gastrectomy in early gastric cancer: early results. Surg Endosc. 2005; 19(2):168-173. [PubMed: 15580441]

13. Hayashi H, Ochiai T, Shimada H, Gunji Y. Prospective randomized study of open versus laparoscopy-assisted distal gastrectomy with extraperigastric lymph node dissection for early gastric cancer. Surg Endosc. 2005; 19(9):1172-1176. [PubMed: 16132323]

14. Huscher CG, Mingoli A, Sgarzini G, Sansonetti A, Di Paola M, Recher A, et al. Laparoscopic versus open subtotal gastrectomy for distal gastric cancer: five-year results of a randomized prospective trial. Ann Surg. 2005; 241(2):232-237. [PubMed: 15650632]

15. Kim YW, Baik YH, Yun YH, Nam BH, Kim DH, Choi IJ, et al. Improved quality of life outcomes after laparoscopy-assisted distal gastrectomy for early gastric cancer: results of a prospective randomized clinical trial. Ann Surg. 2008; 248(5):721-727. [PubMed: 18948798]

16. Sakuramoto S, Yamashita K, Kikuchi S, Futawatari N, Katada N, Watanabe M, et al. Laparoscopy versus open distal gastrectomy by expert surgeons for early gastric cancer in Japanese patients: short-term clinical outcomes of a randomized clinical trial. Surg Endosc. 2013; 27(5):1695-1705. [PubMed: 23247737]

17. Kim HH, Hyung WJ, Cho GS, Kim MC, Han SU, Kim W, et al. Morbidity and mortality of laparoscopic gastrectomy versus open gastrectomy for gastric cancer: an interim report: a phase III multicenter, prospective, randomized Trial (KLASS Trial). Ann Surg. 2010; 251(3):417-420. [PubMed: 20160637]

18. Kim W, Kim HH, Han SU, Kim MC, Hyung WJ, Ryu SW, et al. Decreased morbidity of laparoscopic distal gastrectomy compared with open distal gastrectomy for stage I gastric cancer: short-term outcomes from a multicenter randomized controlled trial (KLASS-01). Ann Surg. 2016; 263(1):28-35. [PubMed: 26352529]

19. Azagra JS, Goergen M, De Simone P, Ibanez-Aguirre J. Minimally invasive surgery for gastric cancer. Surg Endosc. 1999; 13(4):351-357. [PubMed: 10094746] 
20. Uyama I, Sugioka A, Fujita J, Komori Y, Matsui H, Hasumi A. Laparoscopic total gastrectomy with distal pancreatosplenectomy and D2 lymphadenectomy for advanced gastric cancer. Gastric Cancer. 1999; 2(4):230-234. [PubMed: 11957104]

21. Shinohara T, Satoh S, Kanaya S, Ishida Y, Taniguchi K, Isogaki J, et al. Laparoscopic versus open D2 gastrectomy for advanced gastric cancer: a retrospective cohort study. Surg Endosc. 2013; 27(1):286-294. [PubMed: 22733201]

22. Park DJ, Han SU, Hyung WJ, Kim MC, Kim W, Ryu SY, et al. Long-term outcomes after laparoscopy-assisted gastrectomy for advanced gastric cancer: a large-scale multicenter retrospective study. Surg Endosc. 2012; 26(6):1548-1553. [PubMed: 22170319]

23. Lee JH, Ahn SH, Park do J, Kim HH, Lee HJ, Yang HK. Laparoscopic total gastrectomy with D2 lymphadenectomy for advanced gastric cancer. World J Surg. 2012; 36(10):2394-2399. [PubMed: 22674092]

24. Cai J, Wei D, Gao CF, Zhang CS, Zhang H, Zhao T. A prospective randomized study comparing open versus laparoscopy-assisted D2 radical gastrectomy in advanced gastric cancer. Dig Surg. 2011; 28(5-6):331-337. [PubMed: 21934308]

25. Strong VE, Devaud N, Allen PJ, Gonen M, Brennan MF, Coit D. Laparoscopic versus open subtotal gastrectomy for adenocarcinoma: a case-control study. Ann Surg Oncol. 2009; 16(6): 1507-1513. [PubMed: 19347407]

26. Strong VE, Song KY, Park CH, Jacks LM, Gonen M, Shah M, et al. Comparison of gastric cancer survival following R0 resection in the United States and Korea using an internationally validated nomogram. Ann Surg. 2010; 251(4):640-646. [PubMed: 20224369]

27. Hashizume M, Konishi K, Tsutsumi N, Yamaguchi S, Shimabukuro R. A new era of robotic surgery assisted by a computerenhanced surgical system. Surgery. 2002; 131(1 Suppl):S330-S333. [PubMed: 11821833]

28. Son SY, Lee CM, Jung DH, Lee JH, Ahn SH, Park do J, et al. Laparoscopic completion total gastrectomy for remnant gastric cancer: a single-institution experience. Gastric Cancer. 2015; 18(1):177-182. [PubMed: 24477417]

29. Shen WS, Xi HQ, Chen L, Wei B. A meta-analysis of robotic versus laparoscopic gastrectomy for gastric cancer. Surg Endosc. 2014; 28(10):2795-2802. [PubMed: 24789136]

30. Zhang X, Tanigawa N. Learning curve of laparoscopic surgery for gastric cancer, a laparoscopic distal gastrectomy-based analysis. Surg Endosc. 2009; 23(6):1259-1264. [PubMed: 18813988]

31. Hu WG, Ma JJ, Zang L, Xue P, Xu H, Wang ML, et al. Learning curve and long-term outcomes of laparoscopy-assisted distal gastrectomy for gastric cancer. J Laparoendosc Adv Surg Tech A. 2014; 24(7):487-492. [PubMed: 24933012]

32. Jung DH, Son SY, Park YS, Shin DJ, Ahn HS, Ahn SH, et al. The learning curve associated with laparoscopic total gastrectomy. Gastric Cancer. 2016; 19(1):264-272. [PubMed: 25481705]

33. Kunisaki C, Makino H, Yamamoto N, Sato T, Oshima T, Nagano Y, et al. Learning curve for laparoscopy-assisted distal gastrectomy with regional lymph node dissection for early gastric cancer. Surgical Laparosc Endosc Percutan Techn. 2008; 18(3):236-241. 


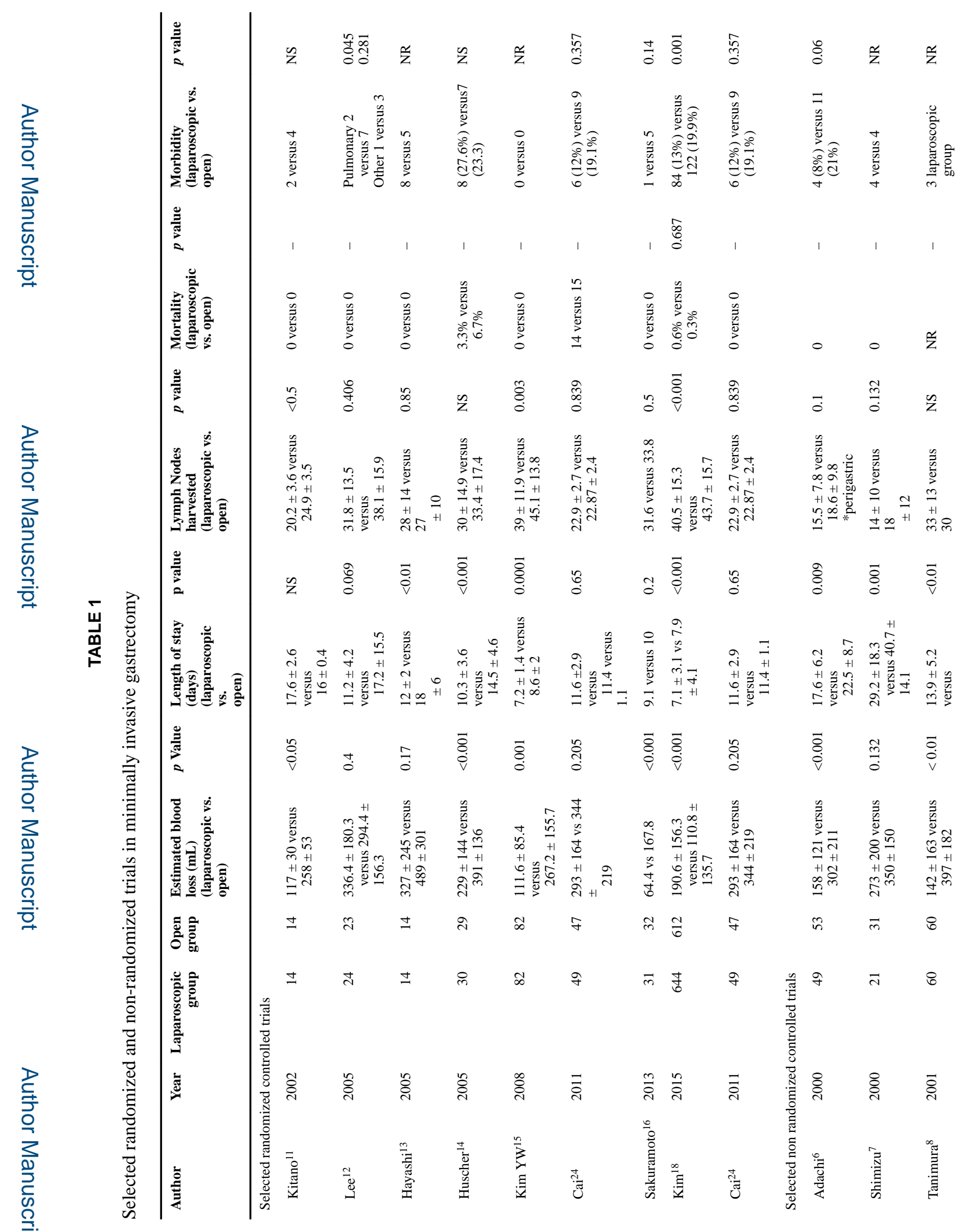

Ann Surg Oncol. Author manuscript; available in PMC 2017 November 01. 


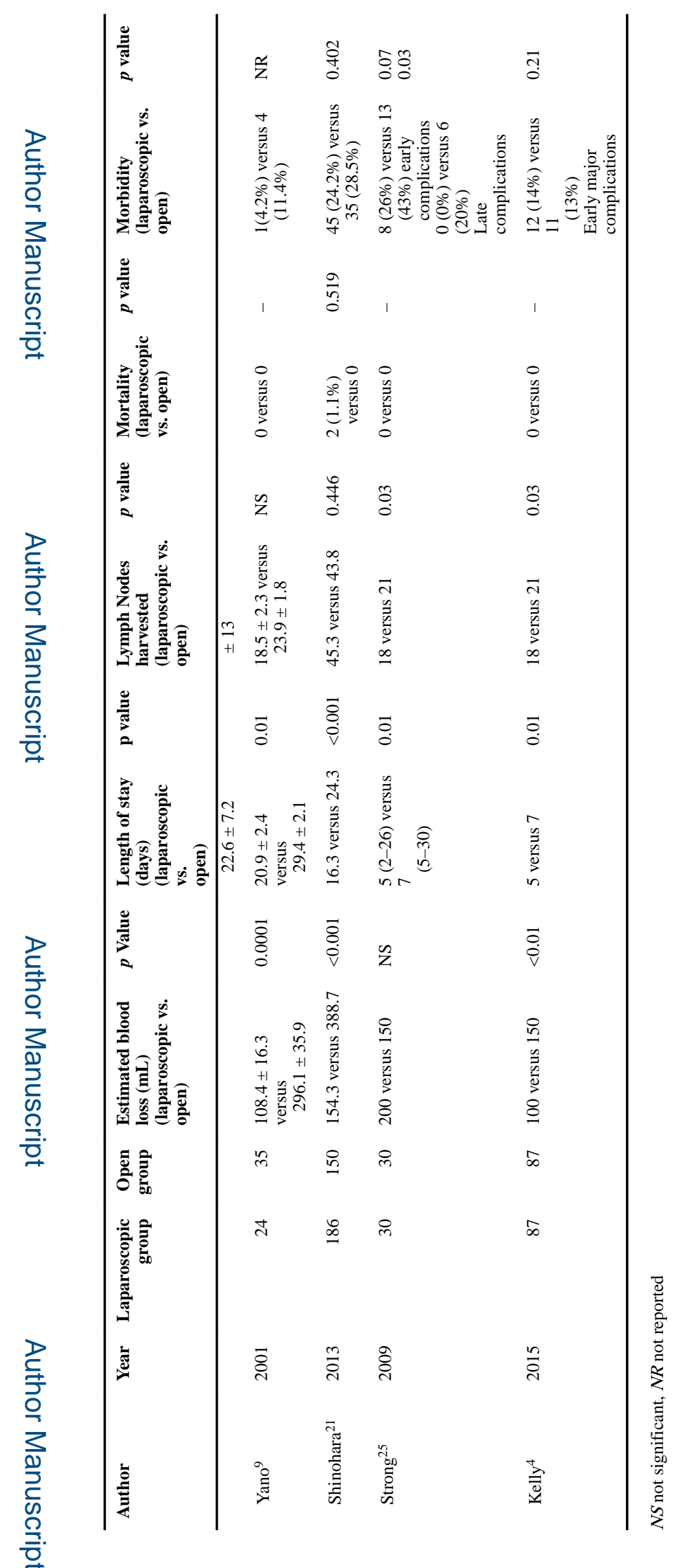

Ann Surg Oncol. Author manuscript; available in PMC 2017 November 01. 